\title{
Psychosocial Safety Climate in Organization: An Overview of Theoretical and Empirical Development
}

\author{
*Nor Hidayah Binti Abd Radzaz, Siti Fatimah Bahari \\ Universiti Teknologi Malaysia Skudai, Johor, Malaysia \\ *hidayahradzaz@gmail.com
}

\begin{abstract}
Psychosocial safety climate (PSC) is a new aspect to be considered in organization in order to overcome work stress issues among employees. The critical study of PSC which build from the foundation of work of psychological safety and safety climate pioneered in 2010 by Maureen F. Dollard and Arnold B Bakker in Australia. The features of climate specifically expected to affect psychological health. New construct of PSC was defined as shared perception of organizational policies, practices and procedures to protect employees' psychological safety and health. Previous studies stated that there are four main elements in PSC which are management commitment, management priority, management and employee participation involvement in stress prevention and organizational communication. It is believed that PSC could be a potential contributor in achieving organization's aim for more positive psychological health environment among employees. Therefore, this paper aims to explicate the theoretical development of PSC and identify the impact on work stress among employees.
\end{abstract}

Keyword: Psychosocial safety climate, psychological health, work stress, job demand-resource model, work characteristic

\section{Introduction}

Many attempted have been made in order to discuss the interaction between work characteristic with stress issue among employees. Amongst the well-establish theoretical explanation on stress interaction is Job Demand-Control (JDC) model by Karasek (1979). This model was mentioned that the cause of job strain were job demand and job control. Regarding to the expended research in stress, JDC model found to be static and not dynamic. Hence, the JDC model was being established by Arnold B. Bakkerinto Job Demand-Resource (JDR) model. The JD-R model postulate that the own specific risk in every occupation associate in the occurrence of work related stress (Bakker \& Demerouti, 2007). Later, an extended research of JD-R was construct a new model of Psychosocial safety climate (PSC) as an antecedent in the occurrence of work stress in organizational (Dollard \& Bakker, 2010). Thus, the aim of this research is to discuss the development of PSC model within theoretical and empirical perspective. Psychosocial safety climate (PSC) was defined as shared perception on policies, practice and procedure to prevent psychological health and safety among employees. The PSC model come out with PSC as the precursor to work condition and in turn burnout, engagement and performance (Idris, Dollard, \& Winefield, 2011). The idea for PSC was derived from the safety climate and team psychology safety literature (Dollard \& Bakker, 2010).

The operation of PSC is believed to be influenced by senior management because they were authorized to control the policies in organization. In this model, PSC was viewed as persecutor for work context including job demand and job resource (Idris, Dollard \& Winefield, 2011) and in turn to predict the consequences of psychological health and engagement (Dollard \& Bekker, 2010).As preventing work stress among employees become important issue, the status of psychology health to be favour by management should be examine in order to verify the balance apprehension between psychological health and productivity among employees (Dollard \& McTernan, 2011). Any decision in an organization is believed to be depending on the authority decisions, which own the legitimate power. With the decision from authority, employee will voluntary follow the decisions (Tyler \& Lind, 1992). Is salient for the manager to favour safety issues and shows the apprehension upon safety towards employees by conceive the policies, practice and procedure that prevent psychological health and safety among employees. Policies, practices and procedures were design according 
to the priority in organization (Zohar \& Luria, 2005). Thus, management commitment is believed to be the vital underlying mechanism in expecting employees' psychology health and safety outcome.

\section{Literature Review}

Psychology safety and safety climate perspective: Psychosocial safety means that an employee able to feel free expressing his/her self without feeling anxious on his/her own fear and negative consequences on his/herself (Khan, 1990). In order to achieve the safety state one should engage with three conditions which are feeling of meaningfulness, safety and availability. In these paper the things to be highlight was the safety condition as the state of safety found to deliberate by positive support from supervisor or management and appreciation by co-worker (May, Gilson, \& Harter, 2004). When management and co-worker were related to employee psychological it creates interaction between one psychology development and his/her social environment which called psychosocial. Psychological safety delivers the meaning of liberty from psychological harm which appears specifically to psychological health and safety. Regarding to the definition of PSC, it been discussed that low PSC was pre-prominent construct of psychosocial risk factor at work and able to generate psychological and social harm in return (Dollard \& Bakker, 2010). Besides experiencing psychology safety, employees also related to psychological climate which a shared believes from team mates upon safety in interpersonal risk taking (Edmonson, 1999). Deliberate from both concept of psychology safety and psychology climate employees who psychologically safe was able to adhere any interpersonal risk which good for learning process. The concept of PSC also being supported from psychology safety model by Edmondson (1999) which to develop psychology safety, it come with context support and team leader coaching beforehand. However in PSC construct, the concept of context support is a bit different when it focused directly to issue of policies, procedure and practice because of the safety climate construct affiliation. The different line between PSC and psychology safety was PSC is believed to be the early cause of working condition outcome and not only indicate working conditions where PSC seem to be affecting psychosocial risk factors such a work pressure and job control (Dollard \& Bakker, 2010).

Another construct that related to PSC was a safety climate construct which introduced by Zohar (1980) 30 years back. Safety climate was integrated from organizational climate concept that defines as shared perception of organizational policies, practice and procedures (Reichers \& Schneider, 1990). Due to the broad concept and unfocused statement, organizational climate was being criticized and Schneider (2000)critically insist that climate should be measure specifically to predict the outcomes such as 'climate for service' and 'climate for safety'. The specific facet for safety was develop by Zohar in 1980 where he define the concept of safety climate as an employees' shared perception towards management commitment and performance via consideration on safety policies, practice and procedure (Neal, Griffin \& Hart, 2000; Weigmann et al., 2002). Regarding to the concept, safety climate refers to climate for physical health and safety and predicting outcomes such as industrial accident (Varon \& Mattila, 2000), safety behavior (Cooper \& Phillips, 2004) and physical injury (Huang et al., 2007). Regardless of the concern on employee physical health and safety, the construction of safety climate was not related to psychological health and safety where the line of research was divided into two separate line (Dollard \& Bakker, 2010). Safety climate research was concentrate on interaction between physical working environment and physical health outcome, where literature of work stress focused on the antecedent of psychosocial risk factor towards psychological health outcome. The construct of PSC is an attempt to bring work issues intervention into wider and holistic perspective where by unify both research line.

Development of PSC Model: In order to operate the PSC concept, Dollard \& Bakker(2010) extended the theory of Job-Demand Resource (JD-R). In JD-R model, employees well-being outcome predict by two separate psychology pathway via workplace characteristics, either job demands (i.e., the physical, social, or organizational aspects of the job that require sustained physical or psychological effort) or job resources (i.e., those aspects of the job that may reduce job demands, are instrumental to achieve work goals, or promote personal growth, learning and development) (Bakker \& Demerouti, 2007). Job demand is postulate health impairment process as the entailment of physical or psychology effort cause with certain physiological and psychological cost (Bakker, Demerouti \& Verbeke, 2004). When the sustained energy unable to encompass job demand, the energy erosion will lead to negative response such as psychological distress. Whilst, job resource work the other way by embark upon intrinsic (fulfill human need) and extrinsic (fulfill work goal) 
motivation where this pathway called a motivation pathway. As a result of motivation pathway the outcome to be predicted is employees' engagement towards organization (Bakker \& Demerouti, 2007) where an ample resource will expected employees' engagement and positive organizational outcome.Theoretically, the function of PSC can be resemble via JD-R model. PSC was considered as an organizational resource that will impact the work characteristic which is job demand and job resource. The possibility is lack PSC in organization lead to poor job design and unremitting demand. Inadequate energy and ability with the demand will have consequnces in work stress (psychological distress) (Miles \& Perrewé, 2011). In PSC perspective the existance of work stress may cause by policies, practices and procedures that lack concern in adjusting appropriate demand at mangeable level (Dollard \& Bakker, 2010). For instance, the situasion happen when procedures for reporting work overload and fatigue did not be outline properly which later increase pressure among employees when they failed to express their feelings. Thus, in high PSC, manager was expected to aware with unappropriate or over workload by design the policies, practices and procedures that protect the employees from work stress induced by work characteristics (Idris et al., 2011).

\section{Empirical Studies on PSC}

Despite the comparatively new argumentation of research in PSC, there been numbers of PSC on extended JD$\mathrm{R}$ model. The earlier years of PSC development research focusing on empirically tested the extended model of JD-R. Research by Dollard and Bekker (2010) among Australian education workers shows that PSC was negatively significant related on the changes of workers' psychological distress and emotional exhaustion as expected from the model. To reach out the boundaries, a research has been conducted in Asian country which is Malaysia(Idris \& Dollard, 2011). The results reported that the public and private employees from state of Selangor experience high job demand and low job resource in low PSC. It shows that PSC was negatively interact with job demand and related positively with job resource. Job demand bears anger and depression as effect of PSC via the mediated path and negatively related to engagement. Regarding to the multigroup analysis, the model found to indifferent between public and private sector. The results also support the extended of JD-R with PSC inclusion as an antecedent.

Dollard et al. (2012) have conducted longitudinal research (24 month) to examine the effect of PSC on psychological strain via work condition among nurses working in Australia remote areas. The results shows that the units are assessed by nurses predict PSC working conditions (workload, control, supervisor support) and psychological stress in nurses working in different units of the same 24-month later. There is evidence that the relationship between the PSC and the group of units' psychological stress has been resolved through Time 2 working conditions (workload, job control) and as Time 1 emotional demands. Researcher was using hierarchical linear models in analysis the findings. The results found to support models with various levels of work stress PSC as the main cause of the cause or reason for causes in work related stress. This study adds literature identifying organizational context factors as the origin of the process of work stress. In addition, a research in Australia was applying PSC in hospital system/organizational intervention. The intervention using PSC system factor and found to be successful as PSC being the indicator on the success health, work outcome and job design (Rickard et al., 2012). They found that psychological distress was significantly decreased and there is significant improvement in job satisfaction across nurses in both hospitals in Northern Territory Australia. The research regarding PSC construct found to show a positive results and support the alteration of JD-R model in append PSC as antecedent for the work characteristic in order to predict the psychology well-being outcomes.

\section{Conclusion}

This study is a response to the concern about organizational contextual factor as the origin of the underneath cause of work stress process. From theoretical analysis and empirical findings it would appear that the low levels of psychosocial safety climate as a latent pathogen to inappropriate working conditions (i.e., high job demands, low job control) that in turn have hit on the effects employees' emotional exhaustion and psychology distress. There is also evidence of a reciprocal relationship between the PSC and work demands. PSC is the effect of psychological stress and also bond with the employee to organization. The PSC model also should be empirically tested with the integrated of ergonomics factors in job design as literature found that poor design in job demand will lead to stress(Miles \& Perrewé, 2011; Iqbal et al., 2011). Our results suggest 
that primary prevention is the vital stress prevention which achieved by targeting the PSC and behavioral change management with the PSC model application as serious attempt from organization toward psychological care of employees.

\section{References}

Bakker, A. B. \& Demerouti, E. (2007). The Job Demands-Resources model: state of the art. Journal of Managerial Psychology, 22(3), 309-328.

Bakker, A. B., Demerouti, E. \& Verbeke, W. (2004). Using the Job Demands-Resources model to predict burnout and performance. Human Resource Management, 43, 83-104.

Cooper, M. D. \& Phillips, R. A. (2004). Exploratory analysis of the safety climate and safety behavior relationship. Journal of Safety Research, 35(5), 497- 512.

Dollard, M. F. \& Bakker, A. B. (2010). Psychosocial safety climate as a precursor to conducive work environments, psychological health problems, and employee engagement. Journal of Occupational and Organizational Psychology, 83, 579-599.

Dollard, M. F. \& McTernan, W. (2011). Psychosocial safety climate: a multilevel theory of work stress in the health and community service sector. Epidemiology and Psychiatric Sciences, 20(4), 287-293.

Dollard, M. F., Opie, T., Lenthall, S., Wakerman, J., Knight, S. \& Dunn, S. (2012). Psychosocial safety climate as an antecedent of work characteristics and psychological strain: A multilevel model. Work \& Stress: An International Journal of Work, Health \& Organisations, 26(4), 385-404.

Edmonson, A. (1999). Psychological safety and learning behavior in work teams. Administrative Science Quarterly, 44, 350-383.

Huang, Y. H., Chen, J. C., Sarah, D., Cigularov, K. \& Chen, P. Y. (2007). Roles of safety climateand shift work on perceived injury risk: A multi-level analysis. Accident Analysis and Prevention, 39, 1088-1096.

Idris, M. A. \& Dollard, M. F. (2011). Psychosocial safety climate, work conditions, and emotions in the workplace: A Malaysian population-based work stress study. International Journal of Stress Management, 18(4), 324-347.

Idris, M. A., Dollard, M. F. \& Winefield, A. H. (2011). Integrating psychosocial safety climate in the JD-R model: A study amongst Malaysian workers. Journal of Industrial Psychology/SA Tydskrif vir Bedryfsielkunde, $37(2), 1-11$.

Iqbal, M., Iqbal, S. A., Rahman, A. N. M. \& Samsuzzoha, A. H. M. (2011). Ergonomics and design. Paper presented at the International Conference on Industrial Engineering and Operations Management, Kuala Lumpur, Malaysia.

Khan, W. A. (1990). Psychological conditions of personal engagement and disengagement at work. Academy of Management Journal, 33(4), 692-724.

May, D. R., Gilson, R. L. \& Harter, L. M. (2004). The psychological conditions of meaningfulness, safety and availability and the engagement of the human spirit at work. Journal of Occupational and Organizational Psychology, 77(1), 11-37.

Miles, A. K. \& Perrewé, P. L. (2011). The relationship between person-environment fit, control, and strain: The role of ergonomic work design and training. Journal of Applied Social Psychology, 41(4), 729-772.

Neal, A., Griffin, M. A. \& Hart, P. M. (2000). The Impact of organizational climate on safety climate and individual behavior. Safety Science, 34(1-3), 99-109.

Reichers, A. E. \& Schneider, B. (1990). Climate and culture: An evolution of constructs. In B. Schneider (Ed.), Organizational climate and culture. San Fransico, CA: Jossey-Bass

Rickard, G., Lenthall, S., Dollard, M., Opie, T., Knight, S. \& Dunn, S. (2012). Organisational intervention to reduce occupational stress and turnover in hospital nurses in the Northern Territory, Australia. Collegian,19(4), 211-221.

Karasek, R. A. (1979). Job demands, job decision latitude, and mental strain: implications for job redesign. Administrative Science Quarterly, 24(2), 285-308.

Schneider, B. (2000). The psychological life of organizations. In A. N. M., M. W. C. P. \& P. M. F. (Eds.), Handbook of organizational culture and climate (pp. 7-21). Thousand Oaks, CA: Sage.

Tyler, T. R. \& Lind, E. A. (1992). A relational model of authority in groups. Advances in Experimental Social Psychology, 25, 115-191. 
Varon, U. \& Mattila, M. (2000). The safety climate and its relationship to safety practices, safety of the work environment and occupational accidents in eight wood processing plants. Accident Analysis and Prevention, 32, 761-769.

Weigmann, D. A., Zhang, H., Thaden, T. V., Sharma, G. \& Mitchell, A. (2002). A synthesis of safety culture and safety climate research. New Jersey: Federal Aviation Administration.

Zohar, D. (1980). Safety climate in industrial organizations: Theoretical and applied implications. J. Appl. Psychol., 12, 78-85.

Zohar, D. \& Luria, G. (2005). A multilevel model of safety climate: cross-level relationships between organization and group-level climates. Journal Applied Psychology, 90(4), 616-628. 